\title{
Discussion on the Distribution of the Burden of Proof of the Damage Caused by Blood Transfusion
}

\author{
Xinhui Zhao \\ Law School \\ Shandong University of Finance and Economics \\ Ji'nan, China
}

\author{
Bingling Han \\ Law School \\ Shandong University of Finance and Economics \\ Ji'nan, China
}

\begin{abstract}
In recent years, medical infringement cases caused by blood transfusions have been commonplace, and the issue of the distribution of burden of proof in such cases has also been controversial. At present, there are still differences in the burden of proof of such infringement in China's legislation. In the judicial practice, the system of responsibility distribution adopted by the judges' courts is also different, which makes the judgment results very different. By analyzing the conflicts under the current law and demonstrating the rationality of the inversion of the burden of proof, combined with the practice of other countries' distribution of such tort liability, it provides future legislation for improving the contradiction between doctors and patients in China.
\end{abstract}

Keywords-blood transfusion; burden of proof; inversion; medical infringement; responsibility distribution

\section{INTRODUCTION}

In recent years, the contradiction between doctors and patients has become more and more tense, and the disputes between doctors and patients have occupied a large proportion in local courts, and cases of blood transfusions have been reported frequently. Such as Li Huicai and Changge City People's Hospital (Henan Changge City People's Court Civil Judgment (2010) Changminchuzi No. 00150), Yu Zhanwei and Anhui Province Suzhou City Hospital, Xiaogan City Blood Station Case (Suzhou City, Anhui Province) Intermediate People's Court (2013) Su Zhongmin San Zhong Zi No. 00591), Yuan Honghe and Jiaozuo Coal Industry (Group) Co., Ltd. Central Hospital Case (Liberation District People's Court (2011) Jieminchuzi No. 595), etc. It is a lawsuit brought by a blood transfusion to a medical institution. However, the application and distribution of the burden of proof in the trial process are quite different. Therefore, It is necessary that the issue of the burden of proof on the harm caused by blood transfusion.

\section{REFLECTION ON MEDICAL INFRINGEMENT CASES CAUSED BY BLOOD TRANSFUSION}

In the first case, Li Huicai and Changge City People's Hospital case, the Changge City Court of Henan Province implemented the practice of inverting the burden of proof during the trial process, so that the hospital bears the burden of proof, that is, after the plaintiff proves the damage result and the blood transfusion relationship, The hospital has the responsibility to prove that there is no causal relationship between the blood transfusion and the damage facts, and there is no fault. In the second case, Zhan Zhanwei and the Suzhou City Hospital of Anhui Province and the blood station of Xiaogan City Center, the Suzhou Intermediate People's Court of Anhui Province advocated in the trial process. In the third case, Yuan Honghe and Jiaozuo Coal Industry (Group) Co., Ltd. Central Hospital case, the People's Liberation District People's Court cited the "Chinese" passed on December 26, 2009. The presumption of fault in Article 58 of the Law of the People's Republic of China on Tort Liability, and whether the plaintiff is responsible for presumptive treatment in the case. As a result, the plaintiff in the first and third cases won the case, and the second case ended in the plaintiff's defeat.

These three cases occurred after the implementation of the Tort Liability Law of the People's Republic of China in 2009. From these cases, it is not difficult to see that the current cases of blood transfusion in China and the allocation standards of the burden of proof adopted by various courts. Not uniform, different value orientations and the results are also affected. To some extent, whoever is burdened with proof will bear a greater risk of losing the case. Therefore, the current general view is that in the case of doctor-patient disputes, where the evidence is located, where the loss is. So, under the current legal framework of China, how are the burden of proof rules for blood transfusions stipulated? With regard to cases of doctor-patient disputes caused by blood transfusion, how to assign the burden of proof is more appropriate? How to improve our country's legislation? Then a series of questions are worth exploring.

\section{CHINA'S PHASEd REVIEW OF SIMILAR MEDICAL \\ INFRINGEMENT LEGISLATION ON BLOOD TRANSFUSION}

The distribution of the burden of proof on the transfusion of blood transfusion is roughly divided into three stages in the development of our country's law: the first stage is before April 1, 2002, that is, the Supreme People's Court promulgated certain provisions on the evidence of civil litigation. (Hereinafter referred to as the "Evidence Regulations") before the implementation; the second stage is after the promulgation of the "Evidence Regulations", to the "Infringement Liability Law of the People's Republic of China" (hereinafter referred to as the "Tort Liability Law") 
before July 1, 2010; the third stage is after the implementation of the Tort Liability Law of July 1, 2010. In the first stage, there is no clear regulation on medical liability in our country's legislation, and there is no provision for proof of responsibility. However, combining some research data and some judicial precedents before 2002, who apart from some courts, advocate who In addition to the evidence and the court's comprehensive judgment, the burden of proof is reversed in the distribution of the burden of proof has been adopted by some courts. In the second stage, according to Article 4, paragraph 8, of the Rules of Evidence, that is to say, the burden of proof of the inversion of the burden of proof, judicial practice in this period often used the defendant (medical institution) to bear the burden of proof, and according to the rules of evidence In the second article, the number of cases in which the burden of proof is reversed in the case of blood transfusion is proportional to the success rate of the plaintiff (victims). Only a small number of courts still insist on comprehensive judgment, and very few courts adopt the responsibility of who advocates the burden of proof. In the third stage, after the entry into force of the Tort Liability Law, there are provisions in Articles 54 and 58 on the distribution of the burden of proof for transfusion. However, these two only stipulate the fault liability and the presumption of fault in three special circumstances. That is to say, the Tort Liability Law after the entry into force does not provide for the inversion of the burden of proof in the case of blood transfusion. Despite this, in the judicial practice of our country, there are still more courts based on the principle of fairness. In order to protect the interests of vulnerable groups of victims, it is need to adopt the principle of inversion of burden of proof. However, some courts adhere to the basic principles of tort liability law and adhere to the principle of fault liability. . However, in general, the current burden of proof on the case of blood transfusion in China's judicial judgment is reversed or mainstream.

Chinese legislators still have not included the burden of proof of medical infringement cases in the Tort Liability Law passed in 2009. The legislators still have more considerations, which can be roughly summarized into four points: First, according to the general legislation of our national law the idea that fault liability occupies the mainstream view of legislation in China, and the relevant medical infringement does not belong to special infringement. This is also reflected in Article 91 of the new "Interpretation of Civil Procedure Law" in 2015: "The people's court shall determine the burden of proof in accordance with the following principles. The undertaking, except as otherwise provided by law: First, the party claiming the existence of the legal relationship shall bear the burden of proof for the basic facts that produce the legal relationship; Second, the party who advocates the change, elimination or nuisance of the legal relationship The basic facts of the change, elimination or nuisance of the legal relationship shall bear the burden of proof." This article can be said to be the first principle of the law of our country (including judicial interpretation). Third, since the implementation of the Rules of Evidence, the number of disputes between doctors and patients has grown exponentially in recent years, and the relationship between doctors and patients has become increasingly tense. Because of the mistrust that leads to violence, the situation of private relief is not uncommon, and the burden of proof is not reversed. Effectively solve the problem fundamentally; thirdly, in the judicial environment in which the burden of proof is reversed, the hospital will often adopt defensive medical care for self-protection, and generally use a full set of inspections of machinery and equipment, which on the one hand causes a large amount of waste of medical resources. It aggravates the economic burden of patients, making the problem of expensive medical treatment more serious. Fourth, comparing the three situations in which the burden of proof on causality is difficult to reverse in the Rules of Evidence, that is, the infringement and common danger caused by environmental pollution. Infringement caused by behavior-induced infringement and infringement caused by medical behavior, it is found that environmental pollution behavior itself is an act that should be strictly stopped, and common dangerous behavior will affect social stability, but medical behavior itself is a legal rescue behavior. The main medical institutions also carry certain public welfare, and they infringe Different real essence, it is the responsibility of the medical tort causation burden of proof and the other two equal treatments is clearly contrary to the principle of fairness. Based on the above considerations, when the legislators of China establish the Tort Liability Law, Article 59 of the second draft of the Tort Liability Law draft may be caused by the medical staff's diagnosis and treatment. In addition to the evidence provided by the medical staff, there is a causal relationship between the diagnosis and the patient's damage. For this practice, although the members of the Standing Committee of the National People's Congress were mixed at the time, and later the academic circles also had various voices to refute, the current legislation in our country still insists on the exclusion of the burden of proof on medical infringement from the law.

\section{ANALYSIS OF CONFLICTS AT THE LEGISLATIVE LEVEL AND DISCUSSION ON THE RATIONALITY OF THE BURDEN OF PROOF}

\section{A. Combining Legislation to Analyze Conflicts}

It is not difficult to find that there is a conflict between the current rules of evidence and the Tort Liability Law in China. As early as 2002, the Rules of Evidence stipulated the burden of proof of inversion of medical liability, but the revised Tort Liability Law of 2009 evaded the allocation of this burden of proof. Most of the cases in judicial practice are based on the responsibility of assigning the burden of proof, not only because the patients themselves are vulnerable groups. Based on the consideration of protecting the weak, the judges usually let the medical institutions bear the burden of proof, and because there is a common The view is that "there is close proximity to evidence" or "professional knowledge" is easy to present evidence to prove the facts claimed by oneself to the extent that the standard of proof is reached. Therefore, it is natural and fair for the class to prove its responsibility. This popular view is actually plausible. As far as medical disputes are concerned, the evidence of fault and causation is not so simple in the medical sense. The fact 
that a party with a close proximity to evidence and a strong ability to prove should be burdened with proof of responsibility has in fact equated the basis for the distribution of responsibility with the responsibility for providing evidence. According to this theory, the doctor should provide all the evidence he has, and if the doctor does not provide evidence, he should bear the consequences of losing the case. Therefore, in the case of medical infringement cases similar to blood transfusion, the burden of proof of inversion has occupied a mainstream position in judicial practice in China, and its rationality remains to be discussed. Moreover, the current conflicts of law make the courts usually perform discretion in judicial practice rather than implementing the distribution rules in accordance with the law. There are many unreasonable points at the legislative level, which greatly impairs the authority and stability of the judiciary. To analyze the main reasons, the author believes that the main reason is that the level and effectiveness of China's legal documents are unclear, the legislative and judicial practices are out of line, and the legislation is not strict.

1) The order and validity of legal documents are unknown: With regard to the rank and effectiveness of China's legal documents, according to Article 8 of the Legislative Law of the People's Republic of China, China's litigation system can only be adjusted by law, and the "Rules of Evidence" promulgated by the Supreme People's Court on medical tort liability The burden of proof is reversed in the General Principles of Civil Law, the Civil Procedure Law and the Tort Liability Law. Look at the effectiveness of the judicial interpretation of the Supreme People's Court in China. The source is the Supreme People's Court's "Provisions on the Judicial Interpretation Work issued by the Supreme People's Court" in 2007. The effectiveness is also self-appointed by the Supreme People's Court, but in practice it is indeed Judicial interpretation serves as the basis for judgment. In the end, how to deal with the conflict between judicial interpretation and legislation, at present, there is no law clearly stipulated in China. However, the author personally believes that judicial interpretation is only a prescriptive document applicable to the law. Its purpose is to better apply the law, safeguard the basic purpose of the law, and clarify the meaning of the legislation when the legal provisions are not clear, and not as applicable in judicial practice. The norm replaces the law, but unfortunately the reality is often not the case. How to treat the relationship between judicial interpretation and legislation is still to be further studied in the future.

2) Judicial practice and legislation are out of touch: Legislators pursue the theoretical and consistency of law in the process of legislation, and often less consider the use of judicial practice; or take into account the use of judicial practice, in order to mediate a certain society, national interests or neutralize a certain The most conservative legislation adopted in a dispute cannot take into account more practical content, and selectively ignores the fact that "judicial rulings have the ultimate settlement of disputes, that is, the parties may not argue for the judicial powers that are in force to appeal to the public power. In this sense In addition, the use of the legal norms in the judicial case most significantly reflects the actual operation of civil norms and systems, and the issues raised by them are also of the most normative significance. This also caused the current legislation and the status quo of judicial disjunction. This is not the only way. At the legislative level, some legal texts are ambiguous or unclear, which makes the normative role of the text body greatly compromised. For example, the first special case in Article 58 of the Tort Liability Law is "violation of law and administration. Regulations, regulations and other regulations on medical treatment regulations, this article can be applied in cases of blood transfusion, because blood transfusion is usually caused by defects in blood collection and input caused by violation of certain medical regulations. In the case of injury, the patient will be injured in the future. In this case, the patient applies the first special case of Article 58 after it proves that it is caused by blood transfusion. To some extent, it is applicable to the inversion of the burden of proof, but obviously This is contrary to the legislator's legislative intent. Therefore, it is necessary to further strengthen the legislative technology.

\section{B. Exploring the Rationality of Adopting the Burden of Proof}

In order to explore the rationality of the provision of the burden of proof on the distribution of burden of proof for transfusion, it is first necessary to clarify the need to reverse the current burden of proof referred to. Tort liability includes causality between damage to facts, illegal acts or technical mistakes, faults and damages, and illegal or technical mistakes. In the case of proof, the facts of infringement of facts and hospitalized blood transfusions are better evidence, and practice is not necessary. Inversion, but whether there is a fault in the medical institution and whether there is a causal relationship between the facts and the results, the medical institution must provide evidence to prove it. If the medical institution has no way to provide relevant evidence, it cannot refuse to accept the court's judgment against itself; and when the medical institution can present evidence to prove that it is not at fault or that there is no harm at all, no matter which one is established, it will hinder the fact of infringement. Second, it is a discussion on the necessity of implementing the burden of proof. No matter which party is assigned to the burden of proof, it is not appropriate. A one-size-fits-all approach is not conducive to judicial practice, just as Marx Weber finally admitted in his book "Social Science Methodology" that he could not create a book in real life. Like the ideal model, legislation cannot include all the circumstances in a single article. In the course of the trial, some other external value interventions will be added, including the judge's free testimony and the judge's group literacy. Moreover, through practice, when medical institutions can present evidence, in order to avoid the inevitable adverse consequences of not providing evidence, they generally have no reservations and the original 
defendant is already in the same position as the evidence superiority. The setting of the burden of proof is reversed to prevent the evidence superiority from concealing the evidence. From this point of view, the purpose of the rule has been reached, and it is extremely unfair to the medical institution to deliberately emphasize the inversion of the burden of proof and the inability to prove the adverse consequences. Finally, regarding the inversion of the infringement of medical infringement in the Tort Liability Law, although it is not perfect in legislation, it is not a onceand-for-all solution to the fuzzification of the law, and even some suspicions that are out of touch with judicial practice, but the change in the revision reflects the fact that the legislators have realized the drawbacks of the inversion of the burden of proof of medical infringement and hope to solve the problem. How to stipulate more properly in the legislation will be a long process of inquiry and argumentation. This article will also be in the process. It's necessary to take a closer look at some of the practices of other countries.

\section{COMBINING WITH WESTERN COUNTRIES' EXPERIENCE}

In view of the above-mentioned deficiencies in China's current legislation, the distribution system of the burden of proof in medical infringement similar to the following countries, and provide reference for the further improvement of China's legislation.

\section{A. Drawing on the US Proof of Reduction}

Due to the particularity of medical behavior, the proof of causality between medical faults and medical behaviors and damage results should be reduced by applicable certification standards. It can be set as a proof of superior evidence by reference to the US civil litigation certification standard to balance the loss of patients. With the aim of no damaging, the healthy medicine has developed. Therefore, the relevant provisions of the United States, appropriately reduce the previous standard of "the evidence is indeed sufficient", divide the different evidence according to its proof of power to prove different facts, and adopt a highly probative proof standard in Japan. If use China's current evidence to prove the standard and the burden of proof reversal system, it will often make the medical institution unable to act as evidence to bear the risk of losing the case because of the insufficient evidence provided, which is partly against the principle of fairness. Therefore, it will prove that the standard reduction will properly balance the sloping responsibility brought by the inversion of the burden of proof, reduce the possibility of defensive medical treatment of medical institutions, and make it assume its due responsibility as a social welfare institution.

\section{B. Seeing the Theory of Proof According to German and Japanese}

Drawing on the German proof theory, the proof is that in general, in the life experience, if A exists, then B usually exists, and the proof of the existence of $\mathrm{B}$ is the proof. If a certain fact exists and it develops in a certain direction, the so-called "finalized phenomenon", it is possible to clarify the existence of certain reasons from this stereotype. The scope of application of the certificate is mainly the fault and causality. For example, if a surgical instrument or gauze is left in the surgical site, the doctor's fault and the causal relationship between the behavior and the damage result can be determined. That is to say, when the plaintiff proposes the fact that the blood transfusion is damaging, and based on experience, the fact of the damage is in great connection with the fault of the medical institution, but the plaintiff cannot present effective evidence of rebuttal, the judge can determine the fact of the damage. There is a causal link between medical behavior and medical behavior. Some scholars have put forward a lot of doctrines on the proof of the testimony. Among them, the Japanese-speaking theory of "certification evaluation", "certification standard theory" and "substantive law theory" are the main ones. In a nutshell, however, the proof theory is a proof method based on experience and judges' freedom of mind. It also provides a new way of thinking in addition to the inversion of the burden of proof for China's system of distribution of burden of proof.

\section{Combining the "Exploration Proof" Theory of the Anglo-American Legal System}

There is a kind of "exploration proof" discussion in the academic circles. It means that the party who does not have the evidence can submit an application to the court based on its own general knowledge of the evidence, requesting the court to obtain the evidence according to the investigation and evidence collection procedure, so that the original defendant It will no longer be limited by the advantages of evidence and can be tried in accordance with general principles. It is not necessary to stipulate the inversion of burden of proof in legislation. And from the perspective of comparative law, in the case of medical infringement lawsuits, countries all over the world generally stipulate that the patient shall bear the burden of proof of medical infringement, which proves that the patient is harmed, the doctor has a diagnosis and treatment fault, and there is a causal relationship between the two. In the new "People's Prosecution Interpretation", Article 112 also has provisions on documentary evidence. "When the documentary evidence is under the control of the other party's party, the party who bears the burden of proof of proof may apply in writing to the people's court to order the other party to submit before the expiration of the time limit for the issuance." This is not an inversion of the burden of proof, but a special case of proof. The civil law countries generally believed that the theory of exploration proved to be opposite to the debate in the traditional sense. However, with the development and integration of individualism, the civil law system of the current stage has also begun to be adopted in practice. China can also consider adopting similar rules in the current cases of blood transfusion and even medical infringement cases to avoid the inadequacies of the burden of proof. 


\section{LEARNING FROM OTHER COUNTRIES TO ESTABLISH A SOUND MEDICAL INSURANCE SYSTEM}

Establish a comprehensive medical insurance system. The consequences of blood transfusion are often serious. Most of the victims suffer from life-threatening diseases such as hepatitis C or AIDS. The cost of medical treatment is huge, resulting in many victims who have no money treatment or are lost because of the long period of litigation. In the best treatment period, regardless of the outcome of the lawsuit, delaying treatment for the victim and his family will cause irreparable harm. The fundamental purpose of the burden of proof of the inversion of the burden of proof is to protect the victim patient to a certain extent, so that it has a lighter burden of proof and ease the current tension between doctors and patients. If a sound medical insurance mechanism is established, the victims will be treated in time, and the relationship between doctors and patients will be gradually harmonious. The situation in which medical institutions are unable to pay the huge medical burden of the victims and evade their responsibilities will also be reduced, which will fundamentally resolve the relevant medical infringement disputes related to blood transfusion.

\section{CONCLUSION}

In summary, at present, the issue of the burden of proof on blood transfusion-induced similar medical infringement cases, although there are various needs to be improved, the legislators have realized that it is necessary to further clarify the importance of the issue of the allocation of burden of proof in medical infringement cases. In the future, it is necessary to gradually change people's prejudice against doctor-patient disputes by checking the cases one by one. At the same time, it is need to improve blood transfusion by establishing a sound medical insurance system and determining the treatment methods for similar special infringement cases and the issue of the burden of proof. However, for the time being, the distribution of responsibility for the inversion of the burden of proof will still occupy a mainstream position in the judicial practice of our country. The improvement of legislation in this aspect still has a long way to go.

\section{REFERENCES}

[1] Dong Chunhua. Empirical Study on the Principle of Liability for Responsibility of Blood Transfusion [J]. Huazhong University of Science and Technology, 2015, (5).

[2] Dong Chunhua. Empirical Study on the Rules of Burden of Torn Causes of Blood Transfusion [J]. Law Forum, 2015, (9).

[3] Xu Wei, Lu Rongrong. Violence and Distrust: Research on Medical Violence in Transitional China: 2000 2006 [J]. Rule of Law and Social Development, 2008(1)

[4] Hu Xuejun. Interpreting the Language of Unattended Comprehension - The Distribution Rules of Burden of Proof in Medical Infringement Litigation [J]. Law Science, 2015(3).

[5] (Germany) Marx Weber. Methodology of Social Science [M]. Translation of Zhu Hongwen. Beijing. Renmin University of China Press, 1999.
[6] Du Yifang. Causality in Japan's Vaccination Case - A JudgmentCentered Investigation [J]. Journal of East China University of Politics and Law, 2014(1).

[7] Zeng Peifang, Duan Wenbo. The Application of German Theory of Proof in the Distribution of Proof Liability in Medical Litigation [J] Politics \& Law, 2007(4). 